\title{
Detección y expresión de una proteína de unión a calmodulina en Plasmodium falciparum
}

\author{
Angela P. Guerra ', Víctor J. Vera ${ }^{2}$, María O. Rojas ${ }^{1,3}$, Moisés Wasserman ${ }^{1,3}$ \\ 1 Grupo de Bioquímica, Instituto Nacional de Salud, Bogotá, D.C., Colombia. \\ ${ }^{2}$ Facultad de Medicina Veterinaria, Universidad Nacional de Colombia, Bogotá, D.C., Colombia. \\ ${ }^{3}$ Facultad de Ciencias, Universidad Nacional de Colombia, Bogotá, D.C., Colombia.
}

\begin{abstract}
Se produjo un anticuerpo monoclonal a partir de proteínas de unión a calmodulina (PUCaM) aisladas por cromatografia de afinidad. Utilizando el inmunoensayo Western blot se detectó una proteína de $30 \mathrm{kDa}$ en extractos de glóbulos rojos parasitados con Plasmodium falciparum. Esta señal no se observó en extractos de eritrocitos no infectados. Adicionalmente, este anticuerpo presentó una reacción con dos bandas de alto peso molecular localizadas en 260 y $240 \mathrm{kDa}$, siendo mucho más intensa la señal para $240 \mathrm{kDa}$. Estas mismas bandas fueron reconocidas por un anticuerpo policlonal anti-espectrina. Lo anterior implica que el anticuerpo monoclonal 1G3 presenta una reacción cruzada con las cadenas de la espectrina y sugiere la presencia de un epítope similar o una estructura estrechamente relacionada en ambas proteínas.

Se estudió la expresión de esta proteína durante el ciclo de desarrollo del parásito y se pudo definir su presencia en las fases tardías del ciclo. La cantidad de la PUCaM de 30 kDa no sólo aumenta de manera absoluta, sino también relativamente con relación a las demás proteínas del parásito. El hecho de que se presente señal en los estadios avanzados de desarrollo y no en el estadio de anillos está indicando que tiene un patrón de expresión diferencial durante el desarrollo del parásito.
\end{abstract}

Palabras clave: Plasmodium falciparum, proteínas de unión a calmodulina.

\section{Detection and expression of a calmodulin binding protein from Plasmodium falciparum}

Monoclonal antibodies were produced against affinity chromatography purified calmodulin binding proteins (CaMBP) of Plasmodium falciparum. Using one of them (1G3) in a Western blot assay, a $30 \mathrm{kDa}$ calmodulin binding protein was detected in extracts of erythrocytes infected with Plasmodium falciparum. This protein was not detected in extracts of non infected erythrocytes. Additionally, the antibody presented a cross reaction with two bands 260 and $240 \mathrm{kDa}$, that reacted also with anti-spectrin policlonal antibody, suggesting that a similar epitope exists in the $30 \mathrm{kDa}$ CaMBP and in spectrin. A study of expression of the $30 \mathrm{kDa}$ CaMBP during the erythrocytic cell cycle showed a stage-specific expression pattern, detecting it only in the late stages of the parasite and not in the younger ones.

Key words: Plasmodium falciparum, calmodulin binding proteins.

Los organismos vivos han establecido varios mecanismos con los cuales traducen las señales extracelulares a un mensaje intracelular que puede ser entendido por la maquinaria bioquímica de la célula (1). En eucariotes, la proteína calmodulina

\footnotetext{
Correspondencia:

mwasserman@hemagogus.ins.gov.co

Recibido: 05/11/01; aceptado: 20/02/01
}

(CaM) está involucrada en la regulación de muchos procesos celulares controlados por las vías de señalización dependientes de $\mathrm{Ca}^{2+}(2)$. Una vez la calmodulina es activada por la unión del calcio, experimenta cambios de conformación que le permiten interactuar con un amplio rango de enzimas y componentes del citoesqueleto (3-6), proteínas que se conocen como de unión a calmodulina, PUCaM. Las PUCaM están 
implicadas en un gran número de funciones celulares ya sea a nivel de membrana plasmática, citoplasma o núcleo, lo que las convierte en elementos claves dentro de los múltiples procesos que se desarrollan en una célula.

En Plasmodium falciparum se ha informado la presencia de calmodulina en el extremo apical de los merozoitos (7) y se conoce que el calcio juega un papel determinante en diferentes eventos del parásito (8-10). Se ha propuesto que una entrada transitoria del catión en el glóbulo rojo puede actuar como un segundo mensajero, disparando una cascada de eventos moleculares que desembocan en la invasión del eritrocito por el parásito (11). Hasta el momento no han sido descritos eventos moleculares que involucren un sistema $\mathrm{Ca}^{2+} / \mathrm{CaM} /$ PUCaM en este parásito y no se han informado proteínas de unión a calmodulina. Para explorar este campo, se produjo un anticuerpo monoclonal contra una proteína de $P$. falciparum que fue aislada en nuestro laboratorio por cromatografía de afinidad utilizando columnas de CaM-agarosa; la afinidad de esta PUCaM por la calmodulina se confirmó en forma independiente con pruebas de coinmuno-precipitación con un anticuerpo contra CaM y por unión a CaM biotinilada de la proteína transferida a una membrana (12).

El anticuerpo monoclonal que aquí se describe nos permitió detectar la proteína de unión a calmodulina de $30 \mathrm{kDa}$ en $P$. falciparum y establecer su patrón de expresión durante el ciclo celular eritrocítico.

\section{Materiales y métodos}

\section{Cultivo de P. falciparum}

Se cultivó la cepa colombiana FCB-2 según el método de Trager y Jensen (13) con eritrocitos humanos grupo 0 positivo al $5 \%$ de hematocrito, en medio RPMI-1640 (Sigma) suplementado con Hepes $25 \mathrm{mM}$, hipoxantina $0,2 \mathrm{mM}, \mathrm{NaHCO}_{3} 21$ $\mathrm{mM}$, glutatión reducido $0,86 \mathrm{mg} / \mathrm{l}$, sulfato de gentamicina $50 \mathrm{mg} / \mathrm{l}$ y suero humano al $10 \%$. Las parasitemias obtenidas en promedio estuvieron entre 5 y $7 \%$.

\section{Obtención del extracto del parásito}

Un cultivo asincrónico con, al menos, 7\% de parasitemia se lavó (700 g, a $5 \mathrm{~min}$ ) dos veces con HBS isotónico (20 mM Hepes ácido, $160 \mathrm{mM}$ $\mathrm{NaCl}$ ); se retiró el sobrenadante y al precipitado obtenido se le agregaron 9 volúmenes de una solución de lisis (saponina $0,15 \%$ en HBS); se mezcló vigorosamente; se incubó durante diez minutos a $4{ }^{\circ} \mathrm{C}$ y posteriormente se centrifugó a $23.000 \mathrm{G}$ por 10 minutos a $4^{\circ} \mathrm{C}$ (Himac centrifugeHitachi rotor RPR 20-2). El precipitado de parásitos se lavó tres veces con HBS $(23.000 \mathrm{~g} /$ 5 min a $4^{\circ} \mathrm{C}$ ) y se le adicionaron 9 volúmenes de buffer de extracción (buffer E: Hepes-KOH 5 mM pH 7,5, $\mathrm{Na}_{3}$ EDTA 0,5 mM, Na ${ }_{3}$ EGTA 0,5 mM, Nonidet P-40 0,05\%) y un coctel de inhibidores de proteasas (PMSF $1 \mathrm{mM}$, benzamidina- $\mathrm{HCl} 0,01$ $\mathrm{mM}$, fenantrolina $1 \mu \mathrm{g} / \mathrm{ml}$, leupeptina $10 \mu \mathrm{g} / \mathrm{ml}$, pepstatina $A 10 \mu \mathrm{g} / \mathrm{ml}$ ). La ruptura de los parásitos se realizó con un homogenizador de teflón a 7/10 de la velocidad máxima (Homogenizer drive unitBellco) por diez veces y en hielo. El homogenizado se sometió a un proceso de centrifugación diferencial empezando a $10.000 \mathrm{~g}$ durante 20 minutos. El sobrenadante se recuperó y se sometió a $100.000 \mathrm{~g}$ durante una hora a $4{ }^{\circ} \mathrm{C}$ (Himac centrifuge Hitachi-rotor RPS 65T-710). Finalmente, el sobrenadante de esta centrifugación se ajustó a 2 mM de DTT y 50 mM Hepes$\mathrm{KOH} \mathrm{pH} \mathrm{7,5.} \mathrm{La} \mathrm{cuantificación} \mathrm{de} \mathrm{la} \mathrm{proteína} \mathrm{total}$ de los diferentes lotes de extracto se realizó por el método de Bradford (14). Los extractos se separaron en alícuotas y se guardaron a $-70^{\circ} \mathrm{C}$.

\section{Inmunización de ratones}

Los resultados obtenidos por Vera permitieron establecer la presencia de 9 PUCaM en $P$. falciparum con pesos moleculares que van desde $240 \mathrm{kDa}$ hasta $20 \mathrm{kDa}$, aproximadamente (12). Con base en los resultados de la cromatografía de afinidad, la coinmunoprecipitación y la unión a calmodulina biotinilada, se escogió la PUCaM de $30 \mathrm{kDa}$ para la producción del anticuerpo monoclonal.

La fracción de la cromatografía de afinidad con las proteínas de unión a calmodulina se concentró por ultrafiltración y se sometió a SDS-PAGE (15) preparativa. Los geles se tiñeron con azul de Coomassie y se cortaron cuidadosamente para retirar la banda de interés (PUCaM de $30 \mathrm{kDa}$ ), con base en el patrón electroforético encontrado 
(12). La banda se homogenizó por pases repetidos a través de dos jeringas y se inocularon aproximadamente $10 \mu \mathrm{g}$ de proteína/inyección en ratones $\mathrm{BALB} / \mathrm{c}$ por vía intraperitoneal. Se hicieron 4 inoculaciones: en la primera (día 1) se utilizó adyuvante completo de Freund; en la segunda (día 7) se usó adyuvante incompleto, y en la tercera (día 14) y cuarta (día 21) PBS ( $\mathrm{NaCl} 8,0 \mathrm{~g} / \mathrm{l}, \mathrm{KCl}$ $0,2 \mathrm{~g} / \mathrm{l}, \mathrm{Na}_{2} \mathrm{HPO}_{4} 1,44 \mathrm{~g} / \mathrm{l}, \mathrm{KH}_{2} \mathrm{PO}_{4} 0,24 \mathrm{~g} / \mathrm{l}, \mathrm{pH}$ $7,2)$. Se realizó una quinta inoculación tres días antes de la fusión. La valoración del aumento del título de anticuerpos se determinó mediante el inmunoensayo Elisa.

\section{Producción de hibridomas}

Las células del bazo del ratón inmunizado se fusionaron con la línea celular de mieloma de ratón X63-Ag 8,653 y polietilenglicol al $41 \%$. La selección de hibridomas se llevó a cabo en medio Dulbeco adicionado con hipoxantina, aminopterina y timidina al $2 \%$ (HAT 50x-Sigma) (16). Los sobrenadantes de los cultivos fueron probados por Elisa para establecer la presencia de anticuerpos. Se escogió uno de los híbridos positivos y se clonó tres veces sucesivas por el método de dilución límite. El tamizaje se hizo mediante Western blot con los sobrenadantes de los pozos de cultivo. El subclón escogido se denominó $1 \mathrm{G} 3$ y se inocularon $2,3 \times 10^{6}$ células en un ratón para producir un tumor ascítico y obtener de éste el anticuerpo. La isotipificación de la subclase del anticuerpo se determinó en el fluído ascítico por un Elisa mediado por antígeno, usando antisueros específicos para clasificar las inmunoglobulinas de ratón (mouse monoclonal antibody isotyping reagents, Sigma).

\section{Inmunoensayo Elisa}

En este ensayo se utilizó un sistema de amplificación biotina-estreptavidina, como buffer de lavado TBST (20 mM TRIS/HCl pH 7,5, 150 $\mathrm{mM} \mathrm{NaCl}, 0,1 \%$ Tween 20), como enzima fosfatasa alcalina y como sustrato p-nitro-fenilfosfato. Placas de poliestireno (Immulon 2-Dynatech) se cubrieron con $100 \mu \mathrm{l}$ del extracto del parásito por cada pozo a una concentración final de $15 \mu \mathrm{g} / \mathrm{ml}$ en tampón carbonato/bicarbonato $0,1.1 \mathrm{M} \mathrm{pH} 9,5$ durante toda la noche $a 4^{\circ} \mathrm{C}$. El antígeno no unido se removió mediante lavados y se adicionaron los sobrenadantes puros de los híbridos durante 1 hora a $37{ }^{\circ} \mathrm{C}$. Se lavó y se adicionaron las antiinmunoglobulinas de ratón marcadas con biotina durante 1 hora a $37^{\circ} \mathrm{C}$. Las placas se lavaron con TBST y se adicionó la fosfatasa alcalinaestreptavidina durante 30 minutos a $37^{\circ} \mathrm{C}$. Se lavó y se adicionó el sustrato $p$-nitrofenilfosfato $1 \mathrm{mg} /$ $\mathrm{ml}$ en buffer sustrato (dietanolamina $1 \mathrm{M}, \mathrm{MgCl}_{2}$ $0,5 \mathrm{mM} \mathrm{pH} \mathrm{9,8)} \mathrm{y} \mathrm{se} \mathrm{incubó} \mathrm{a} \mathrm{temperatura}$ ambiente hasta desarrollo de color durante 30 minutos. La reacción se frenó con $25 \mu \mathrm{L}$ de EDTA $0,1 \mathrm{M}$ y las lecturas se realizaron en un lector de microplacas a una longitud de onda de $405 \mathrm{~nm}$. Como control negativo se utilizó sobrenadante puro de un cultivo de células de mieloma.

\section{Transferencia y Western blot}

El extracto del parásito se sometió a SDS-PAGE (15) y posteriormente se realizó la transferencia en cámara húmeda (Hoefer Scientific Instruments) a membranas de Immobilon PVDF (Millipore) durante 20 horas, 21 voltios y $4{ }^{\circ} \mathrm{C}$ de acuerdo con Towbin (17). Las membranas se cortaron en tiras y fueron bloqueadas durante toda la noche a $4{ }^{\circ} \mathrm{C}$ con una solución de TBST a la que se le añadió $5 \%$ de leche en polvo libre de grasa. Se guardaron a $-20^{\circ} \mathrm{C}$ en la misma solución hasta su uso. Las membranas se lavaron con TBST y se agregaron los sobrenadantes puros de los híbridos clonado, incubándolos durante toda la noche a 4 ${ }^{\circ} \mathrm{C}$. Posteriormente, las tiras se lavaron con TBSTleche y se adicionó anti-inmunoglobulina de ratón biotinilada (Dako) con incubación durante 1 hora a temperatura ambiente. Se lavó con TBST-leche, se agregó la fosfatasa alcalina-estreptavidina (BRL) y se incubó durante 30 minutos a temperatura ambiente. Tanto el anticuerpo secundario como la enzima se agregaron a diluciones previamente estandarizadas. En el último lavado se utilizó TBST sin leche y se adicionó el sustrato NBT/BCIP (Sigma) según indicaciones del fabricante, incubando por no más de 3 minutos.

\section{Estudio de la expresión de la PUCaM de $30 \mathrm{kDa}$}

Se tomaron 4 edades específicas a lo largo del ciclo de vida del parásito: $14,28,40$ y 48 horas. Para realizar este estudio fue necesario recolectar 
parásitos altamente sincrónicos, lo cual se llevó a cabo sometiendo los cultivos a un proceso de muy estricta sincronización y a una muy alta invasión (18-21). Una vez se obtuvieron los cultivos supersincrónicos de las 4 edades, se prepararon los diferentes extractos de acuerdo con la metodología previamente descrita. El diseño experimental que se siguió en el estudio de expresión permitió establecer el comportamiento de la PUCaM desde dos tópicos así:

- determinar la aparición de la proteína de 30 kDa a medida que avanza el ciclo celular del parásito y

- determinar la concentración relativa de la proteína de $30 \mathrm{kDa}$ con respecto a las demás proteínas del parásito.

Para poder evaluar la expresión de la proteína como se mencionó previamente, fue necesario conocer tanto la cantidad de parásitos como la cantidad de proteína presente en cada uno de los cuatro extractos. Así, para determinar la aparición de la proteína durante el ciclo celular, se corrió una electroforesis cuyo gel se sembró con el mismo número de parásitos: $2,7 \times 10^{7}$ parásitos/ carril para cada uno de los cuatro puntos escogidos. Posteriormente, se transfirió a una membrana PVDF y se realizó un Western blot, utilizando como anticuerpo primario el monoclonal 1G3. La segunda determinación se llevó a cabo de la misma forma con la diferencia de que el gel se cargó con la misma cantidad de proteína: 2,3 $\mu \mathrm{g} /$ carril en los cuatro puntos. Se usaron geles con una concentración de acrilamida de $12 \%$ en buffer tris-glicina y condiciones denaturantes.

\section{Resultados}

Producción del anticuerpo monoclonal, isotipificación y detección de la PUCaM de 30 $k D a$

Después de la fusión, los sobrenadantes de los pozos en los que hubo crecimiento se probaron por Elisa para determinar la presencia de anticuerpos y se escogieron 3 híbridos positivos para ser clonados por el método de dilución límite. La clonación de los tres híbridos arrojó 16 clones que fueron probados por Elisa y por Western blot. De ellos se escogió el clon denominado $30 \mathrm{kDaNo}$.3dil\#4 para una nueva clonación y se obtuvieron 8 clones positivos. Finalmente, para garantizar la pureza del clon escogido, se realizó una tercera clonación con 2 (C3 y E9) de los 8 clones anteriores y se obtuvieron 16 clones positivos por Western blot a partir de $\mathrm{C} 3$ y 10 a partir de E9. Todos ellos con excelentes características de crecimiento y de los cuales se seleccionó el clon 1G3 para la producción de fluido ascítico. Con este fluido se realizó la isotipificación por el método de Elisa mediado por antígeno, de acuerdo con las instrucciones del fabricante (Sigma) y se determinó que el anticuerpo monoclonal es una inmunoglobulina de la clase $M$.

En la figura 1, los carriles 2, 3 y 4 muestran el patrón de reconocimiento de 3 sobrenadantes de los 16 clones probados para $\mathrm{C} 3$ y los carriles 5,6 y 7 el patrón de reconocimiento de 3 sobrenadantes de los 10 clones para E9. El carril 2 corresponde

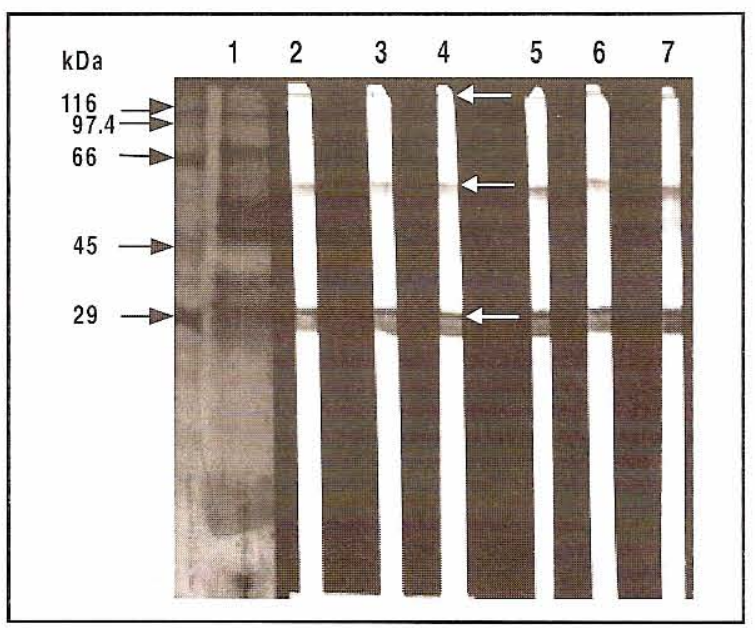

Figura 1. Tamizaje mediante Western blot de los clones C3 y E9.

El extracto del parásito fue sometido a electroforesis denaturante en geles de poliacrilamida ( $112 \%)$ y transferido a membrana PVDF. Para la inmunorreacción, se utilizó como anticuerpo primario los sobrenadantes obtenidos durante la clonación de C3 y E9, un sistema de amplificación biotinaestreptavidina y fosfatasa alcalina. Los carriles 2,3 y 4 muestran el patrón de reconocimiento para 3 de los clones provenientes de $\mathrm{C} 3$ y los carriles 5,6 y 7 el patrón de reconocimiento para 3 de los clones provenientes de E9. El carril 1 corresponde a una sección de la membrana teñida con azul de Coomassie. Los carriles 2 al 7 presentan un patrón de reconocimiento exactamente igual para los 6 clones examinados; se observa una señal muy intensa a la altura de $30 \mathrm{kDa}$ y dos señales adicionales en aproximadamente $60 \mathrm{kDa}$ y $240 \mathrm{kDa}$. El carril 2 corresponde al clon $1 \mathrm{G} 3$, el cual fue escogido para la producción de fluido ascítico. 
al clon 1G3. Los otros 20 clones también fueron probados y mostraron un patrón de reconocimiento exactamente igual (resultados no mostrados). La señal para la PUCaM de $30 \mathrm{kDa}$ fue bastante intensa, aunque se observaron otras bandas de menor intensidad, lo cual sugiere la necesidad de titular el anticuerpo con el propósito de eliminar las interacciones no específicas y disminuir las señales de reacciones cruzadas. Para titular el anticuerpo monoclonal 1G3, se probaron diferentes diluciones del fluido ascítico, escogiéndose 1:1000 ya que en este título se obtuvo un reconocimiento específico para la PUCaM de $30 \mathrm{kDa}$ y el ruido de fondo fue mínimo (figura 2). Adicionalmente, se observaron otras dos señales: una muy tenue en $60 \mathrm{kDa}$ y una muy intensa en aproximadamente $240 \mathrm{kDa}$, señal ésta que no desapareció aún a altísimas diluciones. Al realizar este ensayo en geles con menor porcentaje de acrilamida, se pudo

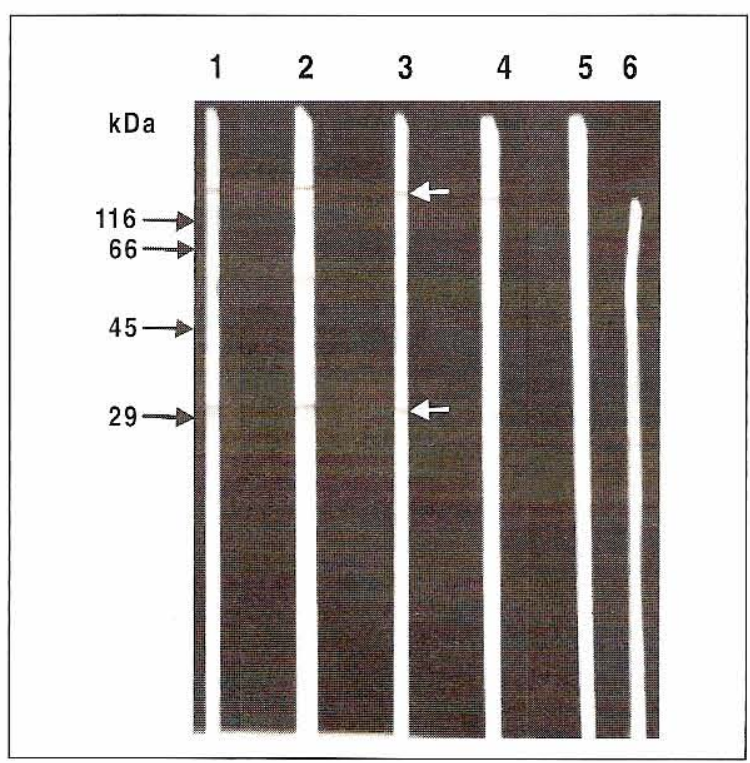

Figura 2. Titulación del anticuerpo monoclonal $1 \mathrm{G} 3$.

El extracto del parásito fue sometido a electroforesis denaturante en geles de poliacrilamida (T12\%) y transferido a membrana PVDF. Para el Western blot, se utilizó como anticuerpo primario el AcMo $1 \mathrm{G} 3$ en diferentes concentraciones, un sistema de amplificación biotinaestreptavidina y fosfatasa alcalina. Carril 1: dilución 1:200 del AcMo 1G3; carril 2: dilución 1:500; carril 3: dilución 1:1.000; carril 4: dilución 1:2.000; carril 5: dilución 1:5.000; carril 6: ensayo control con sobrenadante de células de mieloma. Se escogió como dilución de trabajo 1:1.000, ya que en ésta la señal para $30 \mathrm{kDa}$ es intensa y el ruido de fondo es mínimo. evidenciar que la banda de $240 \mathrm{kDa}$ corresponde realmente a 2 bandas, una de aproximadamente $240 \mathrm{kDa}$ y otra de $260 \mathrm{kDa}$. En la figura $3 \mathrm{se}$ muestran los resultados del Western blot de geles de poliacrilamida al $7 \%$ cargados con extracto del parásito. El carril 1 corresponde al extracto del parásito transferido a membrana y teñido con azul de Coomassie donde se observan dos bandas que migran a la misma altura de la espectrina; en el

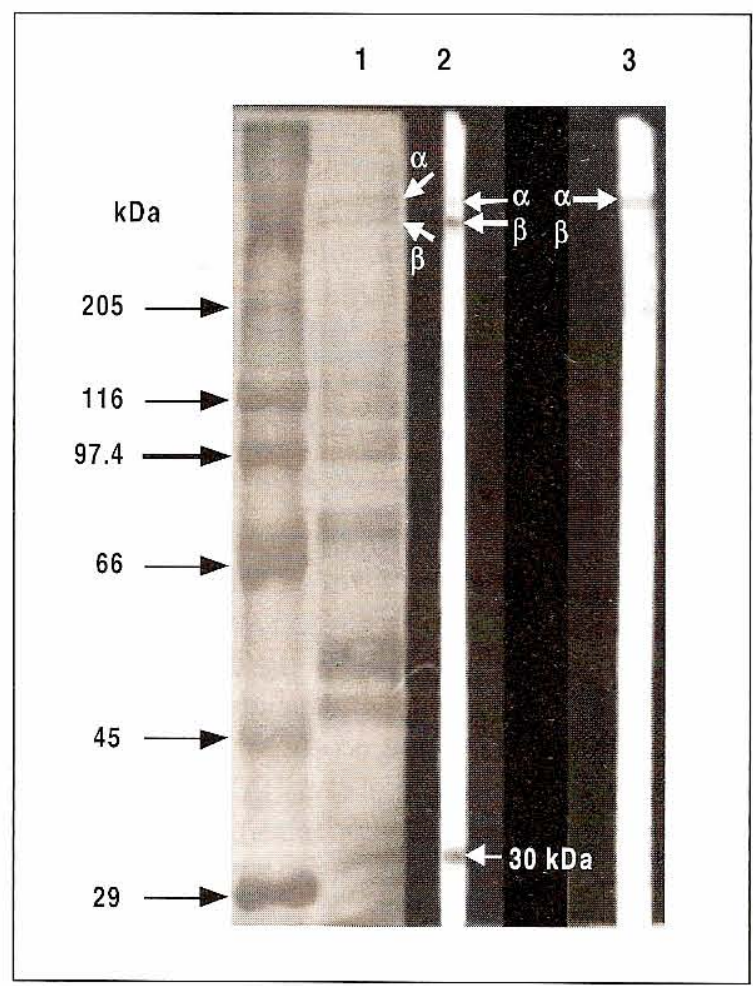

Figura 3. Detección de $\alpha$ y $\beta$ espectrina utilizando el AcMo $1 \mathrm{G} 3$.

El extracto del parásito fue sometido a electroforesis denaturante en geles de poliacrilamida (T7\%) y transferido a membrana PVDF. Para el Western blot se utilizó como anticuerpo primario el AcMo $1 \mathrm{G} 3$ y anti-espectrina humana. Carril 1: sección de la membrana teñida con azul de Coomassie; carril 2: reconocimiento con el AcMo 1G3; carril 3: reconocimiento con el anticuerpo policlonal anti-espectrina humana. El AcMo $1 \mathrm{G} 3$ reconoció 3 bandas, una en $30 \mathrm{kDa}$ y otras dos en $260 \mathrm{kDa}$ y $240 \mathrm{kDa}$, aproximadamente. La anti-espectrina presentó 2 señales, una muy débil en 240 kDa (cadena $\beta$ ) y otra más intensa en 260 kDa (cadena $\alpha$ ). Las bandas reconocidas por la anti-espectrina son aparentemente las mismas bandas de alto peso molecular reconocidas por el AcMo 1G3, aunque la señal obtenida con este último anticuerpo para la banda de $240 \mathrm{kDa}$ (cadena $\beta$ ) es muy intensa y para la banda de $260 \mathrm{kDa}$ (cadena $\alpha$ ) es muy débil. 
carril 2 se utilizó el AcMo 1G3 como anticuerpo primario y se observaron 3 señales, una muy fuerte en $30 \mathrm{kDa}$ y las otras dos en 260 y $240 \mathrm{kDa}$, siendo mucho más intensa la señal para esta última; en el carril 3 se usó anti-espectrina humana como anticuerpo primario y se presentaron dos señales, una muy débil en 240 kDa y una más intensa en $260 \mathrm{kDa}$. Las bandas reconocidas por la anti-espectrina son aparentemente las mismas bandas reconocidas por el AcMo 1G3. Esta reacción cruzada con una dupleta de proteínas localizada en 260 y 240 kDa corresponde a los mismos pesos moleculares informados por Forero (22) y Vera (12) para las cadenas $\alpha$ y $\beta$ de una espectrina putativa presente en extractos radiomarcados de $P$. falciparum. Los anteriores hallazgos nos llevan a sugerir que el anticuerpo monoclonal reconoce un epítope que es compartido por la PUCaM de $30 \mathrm{kDa}$ y por las dos bandas que comigran con espectrina.

\section{Origen de la PUCaM de $30 \mathrm{kDa}$}

Se realizó un Western blot utilizando como antígeno, en el primer carril, extracto de parásito $(6,7 \mu \mathrm{g} /$ carril) y en el segundo carril, extracto de eritrocito no infectado ( $16 \mu \mathrm{g} / \mathrm{carril}$ ) y como anticuerpo primario para ambos ensayos el AcMo 1G3. La figura 4 muestra en el carril 1 una señal a la altura de $30 \mathrm{kDa}$ y en el carril 2, ausencia de la misma. Estos resultados prueban que la PUCaM en estudio proviene del parásito y no del eritrocito.

Adicionalmente, se observó otra señal en el carril 1 que podría corresponder a la $\beta$-espectrina presente en extractos del parásito y en el carril 2 otras 2 señales que corresponden una a la cadena $\beta$ de la espectrina y la otra, posiblemente, a un producto de degradación de la espectrina eritroide. Claramente se evidencia que las señales para estas dos cadenas $\beta$ no se ubican a la misma altura, es decir, la espectrina detectada en el parásito migra diferente a la del eritrocito.

\section{Expresión de la PUCaM de $30 \mathrm{kDa}$}

En el cuadro 1 se observa que la cantidad de proteína total aumenta a medida que progresa el ciclo celular, resultado que está de acuerdo con estudios previos relacionados con la síntesis de macromoléculas donde se informa un comportamiento bimodal para la síntesis de

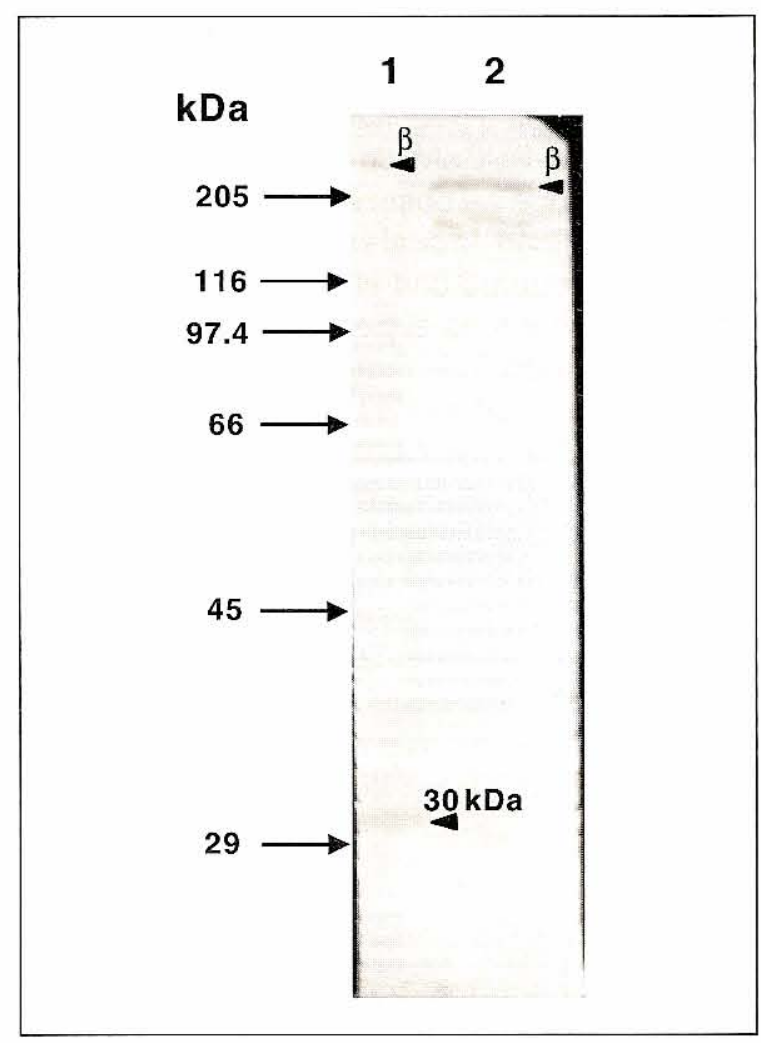

Figura 4. Western blot para confirmar el origen de la PUCaM de $30 \mathrm{kDa}$.

Extracto de $P$. falciparum y extracto de eritrocitos no infectados fueron sometidos a electroforesis denaturante en geles de poliacrilamida (T7\%) y transferidos a membrana PVDF. Para la inmunorreacción, se utilizó como anticuerpo primario únicamente el AcMo 1G3. Carril 1: membrana con extracto del parásito; carril 2: membrana con extracto de eritrocito. En el carril 1 se observa una señal en $30 \mathrm{kDa}$, mientras que en el carril 2 hay ausencia de la misma. Estos resultados indican que la PUCaM de $30 \mathrm{kDa}$ es una proteína del parásito y no del eritrocito. En el carril 1 también se observó una señal en 240 kDa (cadena $\beta$ ), que corresponde a la señal obtenida en el carril 2 en $220 \mathrm{kDa}$ (cadena $\beta$ eritroide). El AcMo $1 \mathrm{G} 3$ reconoce la PUCaM de $30 \mathrm{kDa}$, además, tiene una reacción cruzada con las cadenas de la espectrina, presentando una mayor afinidad con la cadena $\beta$ que con la cadena $\alpha$.

proteínas con un primer pico entre las 20 y las 28 horas y uno mucho mayor entre las 32 y las 48 horas (23).

Los resultados de la figura 5 muestran la presencia de la proteína de interés y nos dan una indicación de su concentración a medida que progresa el ciclo celular, ya que la cantidad de parásitos en 
Cuadro 1. Características de los extractos sincrónicos de $14,28,40$ y 48 horas.

\begin{tabular}{ccc}
\hline $\begin{array}{c}\text { Parásitos } \\
\text { edad/horas }\end{array}$ & $\begin{array}{c}\text { Cantidad de parásitos } \\
\text { recolectada }\end{array}$ & $\begin{array}{c}\text { Proteína total } \\
\mu \mathrm{g}\end{array}$ \\
\hline 14 & $8,1 \times 10^{9}$ & 166,1 \\
28 & $7,1 \times 10^{9}$ & 153,5 \\
40 & $1,6 \times 10^{9}$ & 216,9 \\
48 & $4,1 \times 10^{9}$ & 406,4 \\
\hline
\end{tabular}

todos los puntos seleccionados es la misma ( $\sin$ embargo, se debe tener en cuenta que la cantidad de proteína total va aumentando a medida que el parásito se desarrolla). Se observa una señal a la altura de $30 \mathrm{kDa}$ en los extractos de 40 y 48 horas, mientras que en los extractos de 14 y 28 horas está ausente. Esto indica que la PUCaM de 30 kDa se expresa en una manera estadio-específica durante los estadios tardíos de desarrollo, lo cual concuerda con el segundo pico de síntesis.

En la figura 6 se muestra la presencia de la proteína en relación con la proteína del parásito (la cantidad de proteína es constante en todas las muestras) y el patrón de expresión básicamente es igual al de la figura 5; es decir, se observa una señal a la altura de $30 \mathrm{kDa}$ en los extractos de 40 y 48 horas pero no en los extractos de 14 y 28 horas. Estos resultados refuerzan los anteriores y a la vez muestran cómo esta proteína no sólo sufre un aumento absoluto en el parásito, sino también un aumento relativo con respecto a las demás proteínas del parásito a medida que avanza el ciclo. Es por ello que, teniendo la misma cantidad de proteína en todos los estadios, sólo se puede detectar en los avanzados y no en los tempranos. Posiblemente, esta proteína va sufriendo un efecto acumulativo desde que empieza a sintetizarse hasta llegar a su máxima expresión en parásitos de 48 horas, en los cuales se observa una señal más intensa. Esto debe querer decir, además, que la PuCaM de $30 \mathrm{kDa}$ se libera al medio o se degrada entre la ruptura del esquizonte y la generación de anillos de 14 horas. Los resultados de este ensayo también muestran que el monoclonal $1 \mathrm{G} 3$ reconoce una proteína localizada entre 240 y $260 \mathrm{kDa}$ en los extractos de 14 y 28 horas pero no en los de 40 y 48.

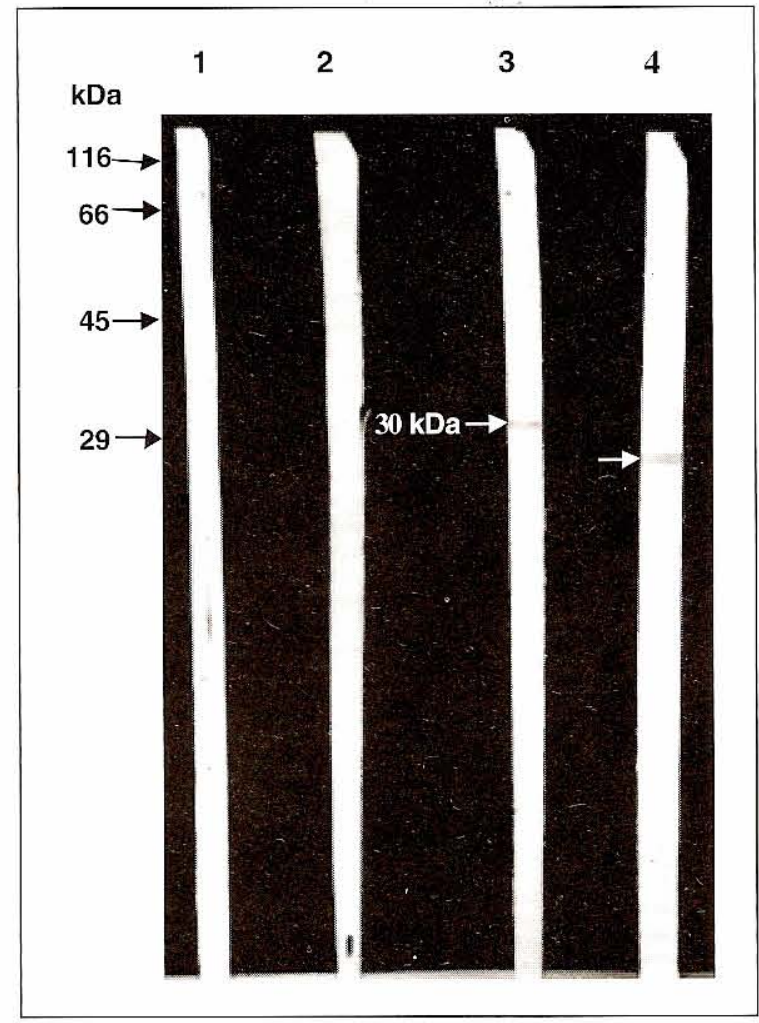

Figura 5. Cinética de expresión de la PUCaM de $30 \mathrm{kDa}$. Extractos de $P$. falciparum de 14, 28, 40 y 48 horas fueron sometidos a electroforesis denaturante en geles de poliacrilamida (T12\%) y transferidos a membrana PVDF. Para el Western blot, se utilizó el AcMo $1 \mathrm{G} 3$ como anticuerpo primario. Carril 1: parásitos de 14 horas; carril 2: parásitos de $28 \mathrm{~h}$; carril 3: parásitos de $40 \mathrm{~h}$; carril 4: parásitos de $48 \mathrm{~h}$. Para las 4 edades, se cargaron $2,7 \times 10^{7}$ parásitos con el propósito de obtener una indicación de la concentración de la PUCaM de $30 \mathrm{kDa}$ a medida que progresa el ciclo celular. La proteína de $30 \mathrm{kDa}$ sólo se detectó en parásitos de 40 y 48 horas, lo que sugiere que la proteína se expresa en una manera estadio-específica.

Por otra parte, teniendo en cuenta la observación relacionada con una localización aparentemente diferente de la señal para la PUCaM de $30 \mathrm{kDa}$ en las tiras de membrana con los extractos de $40 \mathrm{y}$ 48 horas, estos hallazgos nos hicieron sospechar que esta proteína podría estar experimentando modificaciones debidas a eventos de procesamiento. Para evaluar lo anterior, se realizó un nuevo Western blot en las mismas condiciones, pero utilizando una membrana completa (sin separar los diferentes carriles) y así determinar sin lugar a dudas la posición exacta de la señal. 


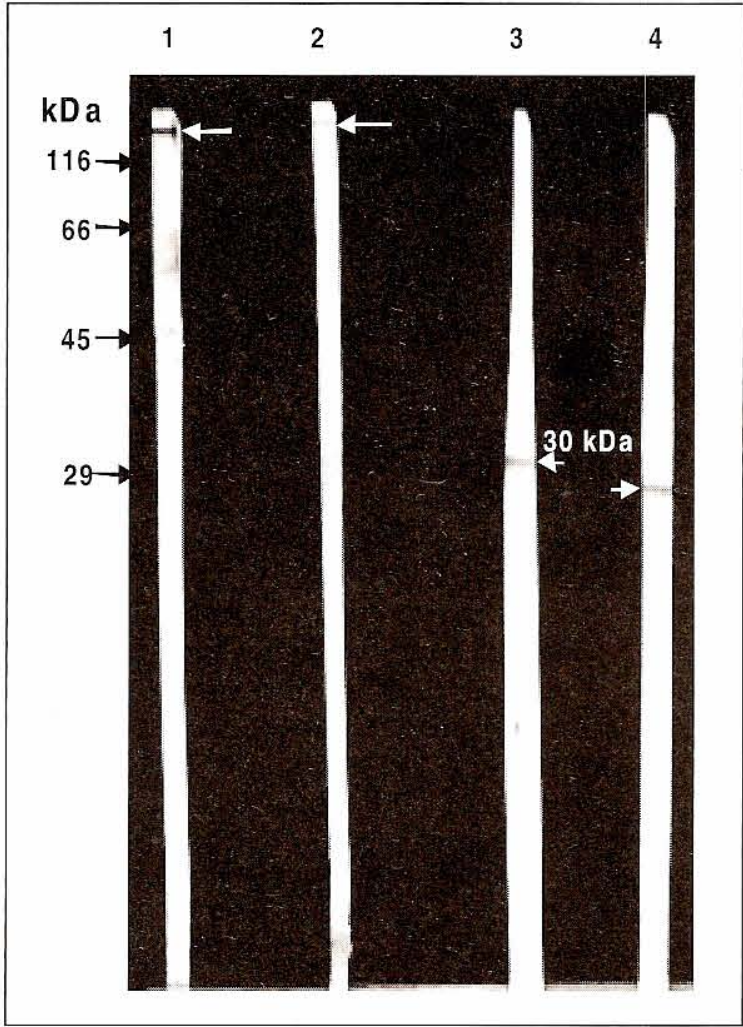

Figura 6. Cinética de expresión de la PUCaM de $30 \mathrm{kDa}$. Extractos de $P$. falciparum de 14, 28, 40 y 48 horas fueron sometidos a electroforesis denaturante en geles de poliacrilamida (T12\%) y transferidos a membrana PVDF. Para el Western blot se utilizó el AcMo $1 \mathrm{G} 3$ como anticuerpo primario. Carril 1: parásitos de 14 horas; carril 2: parásitos de 28 h; carril 3: parásitos de 40 h; carril 4: parásitos de 48 h. Para los cuatro estadios, se cargaron $2,3 \mu \mathrm{g}$ de proteína, con el objeto de establecer la concentración relativa de la proteína de $30 \mathrm{kDa}$.

Los resultados (figura 7) muestran que la señal para la PUCaM tanto en el extracto de 40 como en el de 48 horas está a la misma altura, con lo que se descarta la posibilidad de un procesamiento de la proteína que modifique sensiblemente su peso molecular.

\section{Discusión}

Los hibridomas obtenidos después de la fusión de las células del bazo del ratón (inmunizado con una proteína de unión a calmodulina de 30 kDa de P. falciparum) con las células de mieloma, produjeron un anticuerpo monoclonal con el cual pudimos detectar la proteína en el parásito y establecer su patrón de expresión. Los resultados

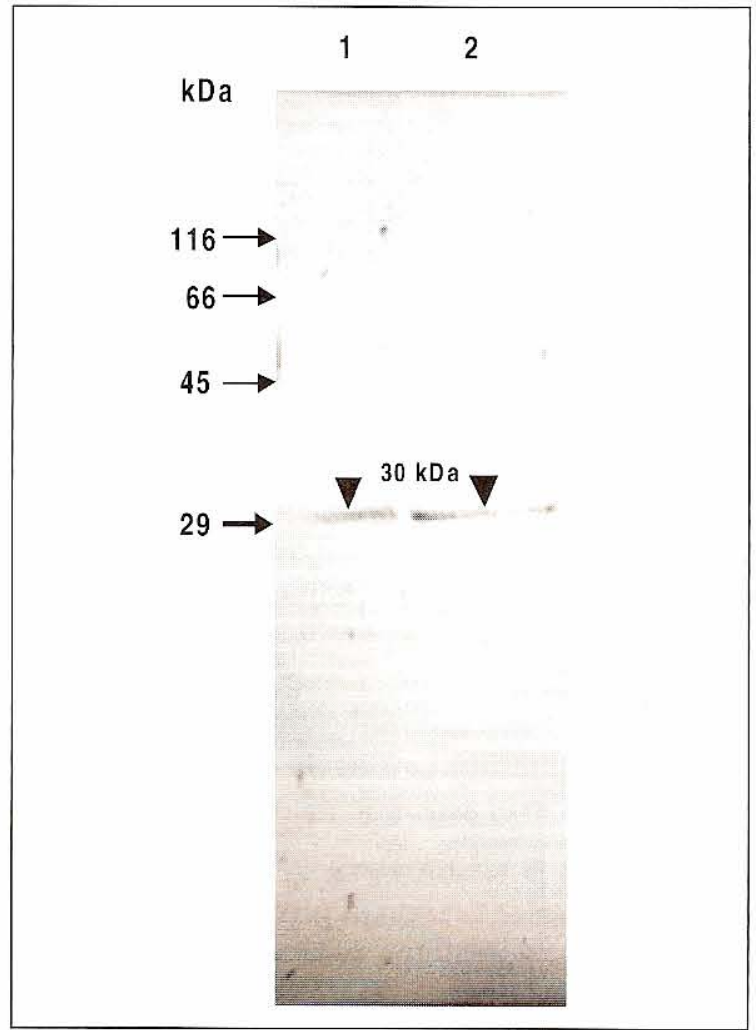

Figura 7. Western blot para definir la localización de la señal de la PUCaM de $30 \mathrm{kDa}$ en parásitos de 40 y 48 horas. Extractos del parásito de 40 y 48 horas fueron sometidos a electroforesis denaturante en geles de poliacrilamida (T12\%) y transferidos a membrana PVDF. La inmunorreacción se realizó con el AcMo 1G3. Carril 1: parásitos de 40 h; carril 2: parásitos de $48 \mathrm{~h}$. En ambos carriles se observa una señal ubicada a la misma altura (30 kDa).

de los Wesiern blot en los cuales se usó extracto del parásito como antígeno, mostraron una señal a la altura de $30 \mathrm{kDa}$, peso molecular que es semejante al de la PUCaM inoculada en los ratones. Esta señal no se observó al utilizar extractos de eritrocitos no infectados, resultado que confirma que esta proteína es propia del parásito. Se observó también una señal tenue en $60 \mathrm{kDa}$, señal que podría corresponder a un precursor de la proteína de $30 \mathrm{kDa}$. Además, el anticuerpo monoclonal $1 \mathrm{G} 3$ presentó una reacción cruzada con dos bandas de alto peso molecular localizadas en 260 y 240 kDa, siendo mucho más intensa la señal para la segunda banda. Estas masas corresponden a las de las cadenas $\alpha$ y $\beta$ de la espectrina previamente informadas en los 
eluidos de extractos del parásito marcados con ${ }^{35} \mathrm{~S}$-metionina que fueron retenidas por una columna de F-actina (22) y por otra de calmodulina (12). Nuestros hallazgos sugieren que las espectrinas presentes en extractos de $P$. falciparum posiblemente no corresponden a contaminación con espectrinas eritroides que quedan al separar los parásitos de los glóbulos rojos, puesto que estas últimas presentan un peso molecular más bajo. En los últimos años se ha descrito un gran número de moléculas de espectrina no eritroide en diferentes tipos celulares de vertebrados, principalmente en cerebro (29) y en las células en ribete de cepillo del intestino delgado (30). También ha sido informada en eucariotes unicelulares como Acanthamoeba (31), Gregarinas (32), Trypanosoma (33) y Toxoplasma gondii (34). En este último organismo se encontró una dupleta de 245 y $240 \mathrm{kDa}$ antigénicamente relacionada con espectrina eritroide humana, proteínas que se localizaron en el complejo apical del polo anterior del parásito.

La espectrina es una proteína del citoesqueleto de las células eucariotas, cuya función general está relacionada con su habilidad para conectar las proteínas integrales de membrana con los filamentos de actina cortical. También se ha sugerido que podría estar involucrada en la organización de dominios receptores, en el control del transporte de vesículas a la membrana plasmática y en la formación y mantenimiento de uniones célula-célula $(24,25)$. Las cadenas $\alpha$ y $\beta$ de la espectrina están compuestas de múltiples repeticiones de 106 residuos; sin embargo, ya que el anticuerpo monoclonal $1 \mathrm{G} 3$ presenta una señal mucho más intensa con la cadena $\beta$, se podría sugerir que el epítope reconocido no está relacionado con estas repeticiones y tal vez se limita a una entidad única de la cadena $\beta$ que no es compartida con la cadena $\alpha$. Dentro de estos dominios propios de la subunidad $\beta(26,27)$ se destacan el dominio de unión a ankirina, el dominio de unión a actina, dos dominios de homología a calponina dentro de la región de unión a actina, un dominio rico en serina en el extremo carboxilo, un dominio rico en prolina que participa en la autoasociación de la espectrina, un dominio rico en serina y treonina que conforma cuatro sitios de fosforilación, una secuencia consenso para caseína cinasa y un dominio de homología a plecstrina $\mathrm{PH}$ (secuencia de aminoácidos que puede plegarse en un módulo compacto y funcional independiente de las secuencias que lo rodean; los dominios $\mathrm{PH}$ pueden asociarse a fosfolípidos o proteínas específicas y promueven la asociación de proteínas señalizadoras con las membranas (28)). Sin embargo, nada se puede aventurar con los actuales datos con respecto a cuál es el epítope que comparten la PUCaM de $30 \mathrm{kDa}$ y la cadena $\beta$ de la espectrina, sobretodo teniendo en cuenta que la cadena $\alpha$ también es reconocida aunque muy débilmente.

Recientemente se ha informado sobre una abundancia significativa de acido glutámico en algunas de las proteínas de Plasmodium y se ha visto que los anticuerpos originados contra estas proteínas tienden a reaccionar cruzadamente con otras proteínas ricas en este aminoácido. Varios antígenos de $P$. falciparum contienen bloques de repeticiones en tandem, ricos en residuos de ácido glutámico, entre los que se encuentran Pf155/ RESA (35), GLURP (36), MESA (37), Ag332 (38), Pf11-1(39), D260 (40) y la fosfoproteína Pc(em)93 en Plasmodium chabaudi (41). Estas repeticiones se caracterizan por la presencia de pares de glutamato seguidas por un residuo hidrofóbico y se presume que este motivo puede ser la base para la reactividad cruzada de los anticuerpos entre las proteínas ricas en ácido glutámico en $P$. falciparum (42-45). La espectrina es rica en glutamato y está compuesta de repeticiones, aunque éstas son más degeneradas que las típicamente encontradas en las proteínas de Plasmodium. Esta característica podría sugerir que el anticuerpo monoclonal $1 \mathrm{G} 3$ reconoce esta clase de repeticiones y podría ser ésta la causa de la reactividad cruzada. Sin embargo, si éste fuera el caso, se esperaría obtener un mayor número de señales en el Western blot, ya que el anticuerpo reaccionaría con algunas de las otras proteínas ricas en ácido glutámico. Lo anterior pone de presente la necesidad de determinar con exactitud cuál es el epítope reconocido y, por otro lado, la de conocer la secuencia completa de la proteína, lo que permitiría deducir homologías con base en motivos o estructuras específicas. 
Observaciones similares al patrón de reconocimiento del AcMo $1 \mathrm{G} 3$ (proteína de interés y reacción cruzada en mayor extensión con la $\beta$ espectrina), se obtuvieron con el AcMo 16,8 dirigido contra una fosfoproteína de $65 \mathrm{kDa}$ de $P$. berghei, rica en ácido glutámico, indicando algún grado de homología entre la espectrina y esa proteína (Wiser M., Universidad de Tulane, comunicación personal).

La isotipificación del anticuerpo monoclonal se realizó sobre fluido ascítico, ya que no se disponía del sobrenadante original del híbrido positivo escogido. No se recomienda determinar la subclase del anticuerpo usando un método directo en líquido ascítico, ya que éste posee inmunoglobulinas propias del ratón. Sin embargo, para obviar el problema, la isotipificación se realizó con un Elisa mediado por antígeno. La placa de micropozos se cubrió con el antígeno en estudio (PUCaM de $30 \mathrm{kDa}$ presente en extractos del parásito) y posteriormente se adicionó el anticuerpo que reconoce específicamente el antígeno, es decir, el anticuerpo monoclonal por tipificar. Luego de la remoción del anticuerpo no unido, se agregó el anticuerpo que reconoce la clase de inmunoglobulina. Hasta aquí se tiene un complejo en el que el anticuerpo que se isotipifica está unido específicamente al antígeno de interés; de esta forma se evitan reacciones inespecíficas con otros anticuerpos del fluido ascítico. Posteriormente, la técnica se continuó revelando con otro anticuerpo que está unido a biotina y con estreptavidina-fosfatasa alcalina como en la metodología normal de la prueba de Elisa.

Con el objeto de definir claramente el patrón de expresión de la PUCaM de 30 kDa, se utilizaron dos ensayos diferentes, ya que si únicamente se analizaban los Western blot cargados con un número igual de parásitos no se podía establecer si la señal observada correspondía en realidad a un determinado estadio del parásito o al aumento normal de la cantidad de proteína a medida que avanza el ciclo y el parásito crece; por esta razón, también se utilizó el sistema cargando en los geles una cantidad igual de proteína. Con base en los resultados de los Western blot de los extractos de parásitos sincrónicos, se puede afirmar que la proteína de unión a calmodulina de $30 \mathrm{kDa}$ es expresada de una manera estadio-específica únicamente en los estadios tardíos de desarrollo y no en el estado de anillos y trofozoítos jóvenes y que este patrón de expresión diferencial demuestra que la PUCaM de $30 \mathrm{kDa}$ es regulada a lo largo del desarrollo del parásito. Debido a que su expresión solo se evidencia a partir de las 40 horas, se podría sugerir que la proteína puede estar involucrada en el ensamblaje de los nuevos parásitos, en el proceso de liberación de los merozoitos o en el de la invasión. Sin embargo, ya que esta proteína no aparece en el estadio de anillos, se podría sugerir que es liberada al medio durante la invasión, que se localiza en el espacio periplásmico o que sufre degradación. De todas formas es necesario llevar a cabo más estudios para determinar su participación en cualquiera de los eventos nombrados.

\section{Agradecimientos}

Este trabajo fue financiado por el Instituto Nacional de Salud, por el BID y por COLCIENCIAS, proyecto 2104-04170-95.

\section{Referencias}

1. Cohen P, Klee CB. Calmodulin. In: Molecular aspects of cellular regulation. Vol.5. Amsterdam: Elsevier Science Publishers; 1988:313.

2. Clapham DE. Calcium signaling. Cell 1995;80:259-68.

3. Klee CB, Crouch TT, Richman PG. Calmodulin. Ann Rev Biochem 1980;49:490-515.

4. Vanber Kum-Mf, George SE, Means AR. Calmodulin activation of target enzimes. Consequences of deletions in the central helix. J Biol Chem 1990;256:3750-6.

5. Heizmann C, Hunziker W. Intracellular calcium-binding proteins: more sites than insights. TIBS 1991;16: 98-103.

6. Ikura M. Calcium binding and conformational response in EF-hand proteins. TIBS 1996;21:14-7.

7. Scheibel LW, Colombani PM, Hess AD, Aikawa M, Atkinson CT, Milhous WT. Calcium and calmodulin antagonists inhibit human malaria parasites $P$. falciparum: implications for drug design. Proc Natl Acad Sci USA 1987;84:7310-4.

8. Wasserman M, Vernot JP, Mendoza PM. Role of calcium and erythrocyte cytoskeleton phosphorylation in the invasión of Plasmodium falciparum. Parasitol Res 1990;76:681-8.

9. Johnson JG, Epstein N, Shiroishi T, Miller LH. Factors affecting the ability of isolated Plasmodium knowlesi merozoites to attach to and invade erythrocytes. Parasitology 1980;80:539-50. 
10. Wasserman M, Alarcón C, Mendoza PM. Effects of $\mathrm{Ca}^{2+}$ on the asexual cell cycle of Plasmodium falciparum. Am J Trop Med Hyg 1982;31:711-7.

11. Wasserman M. The role of calcium ions in the invasión of Plasmodium falciparum comentary. Blood Celis 1990; 16:450-1.

12. Vera V, Wasserman M. Aislamiento y caracterización de proteínas de unión a calmodulina en Plasmodium falciparum. Submitted, 2000.

13. Trager W, Jensen JB. Human malaria parasites in continuos culture. Science 1976;193:673-5.

14. Coligan JE, Dunn BM, Ploegh HI, Speicher DW, Wingfield PT. Current protocols in protein science. New York: John Wiley \& Sons; 1996:3.4.10-3.4.11.

15. Laemmli UK. Cleavage of structural proteins during assembly of the head of bacteriophage T4. Nature 1970; 227:680-5.

16. Zola H, Brooks D. Techniques for the production and characterization of monoclonal hybridoma antibodies. In: Hurrell JGR, editor. Monoclonal hybridoma antibodies: techniques and applications. Boca Raton: CRC Press; 1982

17. Towbin H, Staehelin T, Gordon J. Electrophoretic transfer of proteins from polyacrylamide gels to nitrocellulose sheets: procedure and some applications. Proc Nat Acad Sci USA 1979;76:4350-4

18. Rojas MO, Wasserman M. Supersincronización del crecimiento in vitro de Plasmodium falciparum. Biomédica 1987;7:75-80.

19. Lambros C, Vanderverg J. Synchronization of $P$. falciparum erythrocytes stages in culture. J Parasitol 1979;65:418-20.

20. Rivadeneira E, Wasserman M, Espinel C. Separation and concentration of schizonts of Plasmodium falciparum by Percoll gradients. J Protozool 1983;30: 367-70.

21. Vernot JP, Wasserman M. Plasmodium falciparum: increased and multiple invasion during short periods of time. J Protozool 1990;37:47-9.

22. Forero C. Proteínas de unión a actina en Plasmodium falciparum (tesis). Bogotá (Colombia): Departamento de Química, Universidad Nacional de Colombia; 1996.

23. Rojas MO, Wasserman M. Temporal relationships on macromolecular synthesis during the asexual cell cycle of Plasmodium falciparum. Trans R Soc Med Hyg 1985; 79:792-6.

24. Björk J, Lundberg S, Backman L. Characterization of the binding of calmodulin to non-erythroid spectrin. Eur J Cell Biol 1995;66:200-4.

25. Hu RJ, Watanabe M, Bennett V. Characterization of human brain cDNA encoding the general isoform of beta-spectrin. J Biol Chem 1992;267:18715-22.
26. Dhermy H. The spectrin super-family. Biol Cell 1991;71: 249-54.

27. Viel A, Branton D. Spectrin: on the path from structure to function. Curr Op Cell Biol 1996;8:49-55.

28. Pawson T. Protein modules and signalling networks. Nature 1995;373:573-6.

29. Bennett V, Davis J, Fowler WE. Brain spectrin, a membrane associated protein related in structure and function to erythrocyte spectrin. Nature 1982;299:12631.

30. Glenney JR Jr, Glenney P, Weber K. Erythroid spectrin, brain fodrin and intestinal brush border protein (TW $260 / 240$ ) are related molecules containing a common calmodulin-binding subunit band to a variant cell type specific unit. Proc Natl Acad Sci (USA) 1982; 79:40025 .

31. Pollard TD. Purification of a high molecular weight actin filament gelation protein from Acanthamoeba that shares antigenic determinants with vertebrate spectrins. J Cell Biol 1984;99:1970-80.

32. Ghazali M, Philippe M, Deguercy A, Gounon P, Gallo JM, Schrével J. Actin and spectrin-like $(\mathrm{Mr}=260$ $240,000)$ proteins in Gregarines. Biol Cell 1989;67:17384.

33. Alcina A, Hargreaves AJ, Avila J, Hesketh JE, Fresno $M$. The detection of a spectrin-like protein in Trypanosoma cruzi with a polyclonal antibody. Cell Biol Int Rep 1988;12:979-85.

34. Ghazali M, Rodier MH, Moudni B, Babin P, Fernandez B, Jacquemin JL. Detection and immunolocalization of human erythrocyte spectrin immunoanalogues in Toxoplasma gondii. J Euk Microbiol 1995;42:427-33.

35. Coppel RL, Cowman AF, Anders RF, Bianco AC, Saint RB, Lingelbach KR, et al. Immune sera recognize an erythrocyte Plasmodium falciparum antigen composed of repeated amino acid sequences. Nature 1984;310:789-92.

36. Borre MB, Dziegiel M, Hogh B, Petersen E, Rieneck $\mathrm{K}$, Riley E, et al. Primary structure and localization of a conserved immunogenic Plasmodium falciparum glutamate rich protein (GLURP) expressed in both the preerythrocytic and erythrocytic stages of the vertebrate life cycle. Mol Biochem Parasitol 1991;49:119-31.

37. Coppel RL. Repeat structures in a Plasmodium falciparum protein (MESA) that binds to human erythrocyte protein 4.1. Mol Biochem Parasitol 1992;50: 33547.

38. Mattei D, Scherf A. The Pf332 gene of Plasmodium falciparum codes for a giant protein that is translocated from the parasite to the membrane of infected erythrocytes. Gene 1992;110:71-9.

39. Scherf A, Carter R, Petersen C, Alano P, Nelson R, Aikawa M, et al. Gene inactivation of Pf11-1 of 
Plasmodium falciparum by chromosome breakage and healing-identification of a gametocyte-specific protein with a potential role in gametogenesis. EMBO J 1992;11: 2293-301.

40. Barnes DA, Wollish W, Nelson RG, Leech JH, Petersen C. Plasmodium falciparum: D260, an intraerythrocytic parasite protein, is a member of the glutamic acid dipeptide-repeat family of proteins. Exp Parasitol 1995;81:79-89.

41. Giraldo LE, Grab D, Wiser MF. Molecular characterization of a Plasmodium chabaudi erythrocyte membrane-associated protein with glutamate-rich tandem repeats. J Eur Microbiol 1998;45:528-34

42. Mattei D, Berzins $\mathrm{K}$, Wahlgren $\mathrm{M}$, Udomsangpeteh R, Perlmann P, Griesses HW, et al. Cross-reactive antigenic determinants present on different Plasmo- dium falciparum blood-stage antigens. Parasite Immunol 1989;11:15-30.

43. Ahlborg N, Berzins K, Perlmann P. Definition of the epitope recognized by the Plasmodium falciparumreactive human monoclonal antibody 33G2. Mol Biochem Parasitol 1991;46:89-96.

44. Wahlin B, Sjolander A, Ahlborg N, Udomsangpetch R, Scherf A, Mattei D, et al. Involvement of Pf155/ RESA and cross-reactive antigens in Plasmodium falciparum merozoite invasion in vitro. Infect Immun 1992;60:443-9.

45. Giraldo LE, Jennings GJ, Deleersnijder W, Hamers-Casterman C, Wiser MF. Characterization of a Plasmodium chabaudi gene encoding a protein with glutamate-rich tandem repeats. Parasitol Res 1999; 85:41-6. 